ISAHP Article: Mu, Saaty/A Style Guide for Paper Proposals To Be Submitted to the International Symposium of the Analytic Hierarchy Process 2014, Washington D.C., U.S.A.

\title{
AN AHP MODEL TO DESIGN MOBILE APPLICATIONS
}

\author{
Emre Çimen \\ Industrial Engineering Department \\ Anadolu University \\ Eskisehir, TURKEY \\ E-mail: ecimen@anadolu.edu.tr \\ Gürkan Öztürk \\ Industrial Engineering Department \\ Anadolu University \\ Eskisehir, TURKEY \\ E-mail: gurkan.o@anadolu.edu.tr
}

\begin{abstract}
There are millions of applications in the mobile app markets. Everyday, lots of apps are supplied to these markets. While some of them get high market shares, the others do not. It is really important to know, how an app can be successful in the markets, before submitting the app to the store. In this study we developed an AHP model to depict design rules for messaging mobile applications. In this way, a mobile app developer can weigh the factors ( i.e., graphics, social network support, etc.) according to their relative importance.
\end{abstract}

Keywords: User Priorities, Mobile Apps, AHP, Factor Analysis 


\section{Introduction}

There are a lot of markets for mobile apps. Markets that have more customers are Apple's App Store and Google Play. The other markets are Nokia Ovi Store and Windows App Store. According to gigaom.com Apple lead the market with 59.6\%, with 591,428 apps. Google Play follows with $32.3 \%$. The others have about 80000 apps and total apps in the markets are about 1 million. Apple's developers are adding about 1,000 new apps a day while Android developers are uploading about 1,400 a day. Juniper Research believes app revenues can hit $\$ 32$ billion by 2015 . Although the revenues are with these high values, the competition in the market is very strong. There are lots of apps and some of them are downloaded millions in a short period while many of them are downloaded only a few. It is really important to know, how an app can be successful in the markets, before designing and submitting the app to the store. Which factors affect consumers/users to buy an app? In this study we developed an AHP model to depict importance of design criteria for messaging mobile applications. The category of the app is also very important to determine the effect of the factors. While aesthetic factors may be important for some apps, it may not be important for others. We worked on messaging apps because people use these apps extensively and the growth of this category is $203 \%$ in last year according to Flurry Analytics.

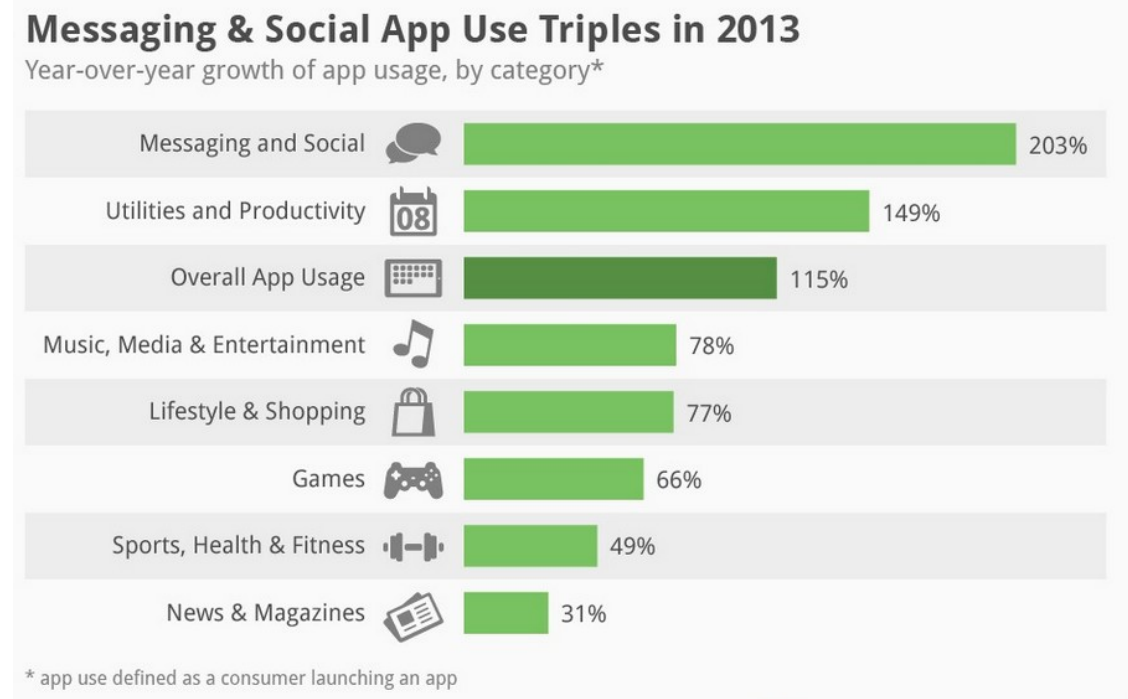

Factors affecting consumers are considered in three main groups: general, aesthetic and technical. Sub- factors are also dealt under main factors. 21 mobile app users weighted these factors with respect to each other. Weights are collected via Google forms. Geometrical means of the weights are used to develop AHP model with three levels.

\section{$1 \quad$ Literature Review}

Mobile app topic is pretty new area for researchers. There are some papers about understanding users behaviors but they do not use AHP directly. Benbunan-Fich R. and Benbunen A. (2007) tried to to understand how users, accustomed to using their handsets 
as talking devices, download applications and navigate through data. Liu C. et al. (2011) aimed to serve as a reference point and guide for developers and practitioners interested in using iOS as a platform for m-health applications, particular from the technical point of view. Holzer A. and Ondrus J. (2011) took a developer's perspective in order to explore how the identified trends would impact the mobile application development markets. Chen Z. et al. (2011) published a survey Chinese consumers' perception of mcommerce applications. Chong A. et al. (2012) published a paper with title "Predicting consumer decisions to adopt mobile commerce: Cross country empirical examination between China and Malaysia". Tiarawut S. (2013) reviewed trends on mobile technology in the mobile ecosystem and mobile application market.

\section{Objectives}

The objective of this work is to determine factors that affecting messaging mobile app users. With result of this study developers can consider some specific factors. They also can improve their app's important weaknesses and do not waste time with unimportant factors.

\section{Research Design/Methodology}

We design AHP model with three levels to understand user's behavior about messaging apps and determine important factors for them. Considered main factors are general, technical and aesthetic factors. Profile photo, current user interface - background and physical effects are considered in aesthetic factors. General factors are price, user points - reviews and number of friends that use the app. Technical factors divided two as order qualifiers and order winning factors. Order qualifiers factors are easiness of typing, fast sending, voice messaging, picture -video messaging and emoji support. Lastly order winning factors are determined as game support with friends, caricature messaging, support of hand-writing and social media support.

\section{Data/Model Analysis}

An AHP model with three levels is developed to determine the important factors for messaging apps. 21 messaging app user weighted each factor with respect to others. 1-9 AHP scale used for weights. Geometrical means of each comparison calculated and used in the AHP model. 


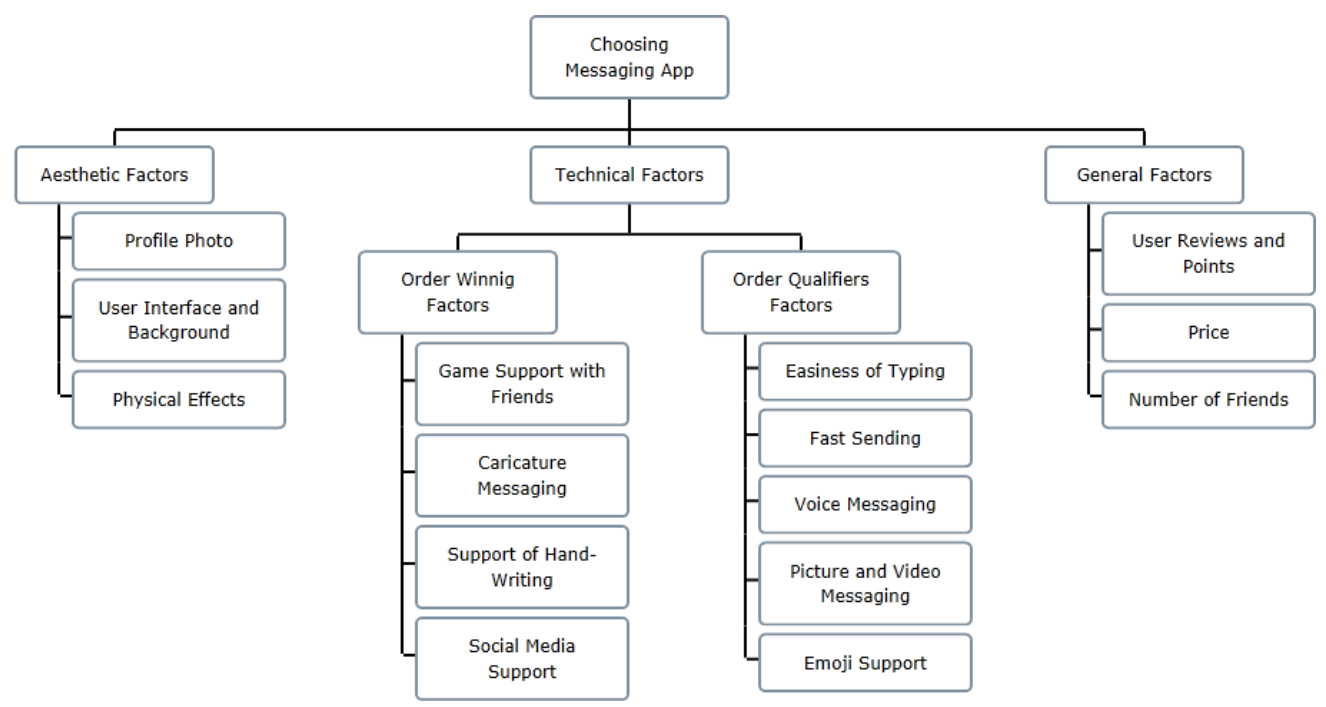

Hierarchical order of the factors can be seen in the figure.

\section{Limitations}

Weights are determined by 21 messaging app users. That will be better with more users.

\section{Conclusions}

As a result of this work, important factors for messaging apps are determined with threeleveled AHP model. According to results the most important factor group is general factors with $61.49 \%$. Technical factors are the second important group with $26.83 \%$.

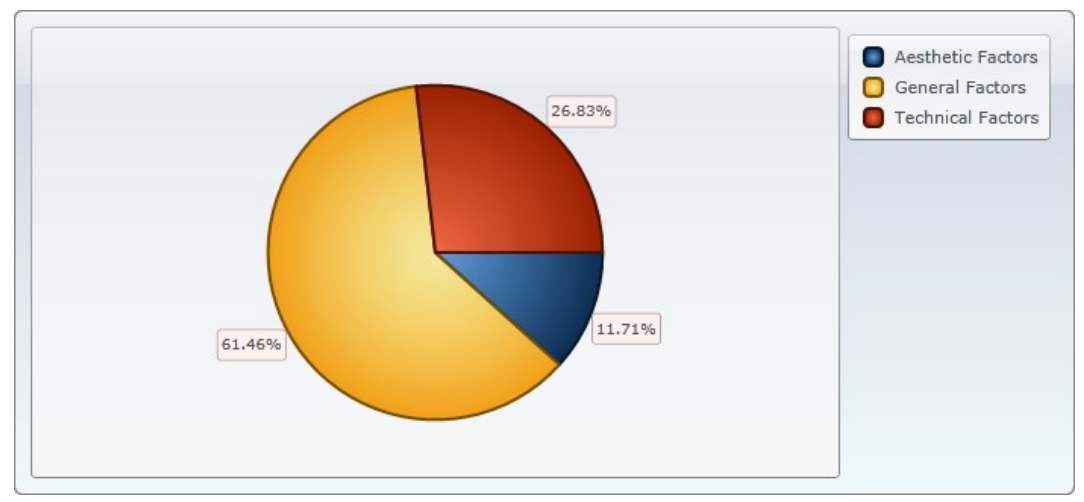

In technical factors, order winning factors are more important than order qualifiers factors with $62 \%$. Social media support (40.79\% local) and game support with friends (34.94\% local) are more important than the others in order winning factors. 
IJAHP Article: Mu, Saaty/A Style Guide for Paper Proposals To Be Submitted to the International Symposium of the Analytic Hierarchy Process 2014, Washington D.C., U.S.A.

Fast message sending (38.13\% local) and easiness of typing (36.87\% local) are more important than the others in order order qualifiers factors.

Display form of the profile pictures $(61.46 \%$ local) is choosen the most important factor in aesthetic factors.

Whole factor list with local and global weights can be seen in the table:

\begin{tabular}{|l|l|l|}
\hline Criterion & Global weight [\%] & Local weight [\%] \\
\hline Choosing Messaging App & 100 & 100 \\
\hline General Factors & 61.46 & 61.46 \\
\hline Price & 37.78 & 61.46 \\
\hline Technical Factors & 26.83 & 26.83 \\
\hline Order Winning Factors & 16.64 & 62.04 \\
\hline Number Of Friends & 16.49 & 26.83 \\
\hline Aesthetic Factors & 11.71 & 11.71 \\
\hline Order Qualifiers Factors & 10.18 & 37.96 \\
\hline User Peviews and Points & 7.2 & 11.71 \\
\hline Profile Photo & 7.2 & 61.46 \\
\hline Scial Media Support & 6.79 & 40.79 \\
\hline Game Support with Friends & 5.81 & 34.94 \\
\hline Fast Sending & 3.88 & 38.13 \\
\hline Easiness of Typing & 3.76 & 36.87 \\
\hline User Interface and Background & 3.14 & 26.83 \\
\hline Caricature Messaging & 2.98 & 17.9 \\
\hline Picture and Video Messaging & 1.51 & 14.8 \\
\hline Physical Effects & 1.37 & 11.71 \\
\hline Support of Hand Writing & 1.06 & 6.37 \\
\hline Emoji Support & 0.61 & 6.01 \\
\hline Voice Messaging & 0.43 & 4.19 \\
\hline & & \\
\hline
\end{tabular}

\section{Key References}

Benbunan-Fich, R. and Benbunen, A. Understanding user behavior with new mobile applications. Journal of Strategic Information Systems 16 (2007) 393-412.

Liu C. et al. Status and trends of mobile-health applications for iOS devices: A developer's perspective. The Journal of Systems and Software 84 (2011) 2022-2033. 
IJAHP Article: Mu, Saaty/A Style Guide for Paper Proposals To Be Submitted to the International Symposium of the Analytic Hierarchy Process 2014, Washington D.C., U.S.A.

Holzer A. and Ondrus J. Mobile application market: A developer's perspective. Telematics and Informatics 28 (2011) 22-31.

Chen Z. et al. A Survey Study on Consumer Perception of Mobile-Commerce Applications. Procedia Environmental Sciences 11 (2011) 118 - 124.

Chong A. et al. Predicting consumer decisions to adopt mobile commerce: Cross country empirical examination between China and Malaysia. Decision Support Systems 53 (2012) $34-43$.

Tiarawut S. Mobile Technology: Opportunity for Entrepreneurship. Wireless Pers Commun (2013) 69:1025-1031. DOI 10.1007/s11277-013-1062-7.

Make It Rational, https://makeitrational.com/demo/decision-making-software

Mashable, http://mashable.com/2014/01/14/mobile-app-use-2013/

Gigaom, http://gigaom.com/2011/12/02/its-a-1-million-mobile-app-world/ 